\title{
A 10-Year Retrospective of Research in Health Mass Media Campaigns: Where Do We Go From Here?
}

\author{
SETH M. NOAR \\ Department of Communication, University of Kentucky, Lexington, \\ Kentucky, USA
}

\begin{abstract}
Mass media campaigns have long been a tool for promoting public health. How effective are such campaigns in changing health-related attitudes and behaviors, however, and how has the literature in this area progressed over the past decade? The purpose of the current article is threefold. First, I discuss the importance of health mass media campaigns and raise the question of whether they are capable of effectively impacting public health. Second, I review the literature and discuss what we have learned about the effectiveness of campaigns over the past 10 years. Finally, I conclude with a discussion of possible avenues for the health campaign literature over the next 10 years. The overriding conclusion is the following: The literature is beginning to amass evidence that targeted, well-executed health mass media campaigns can have small-to-moderate effects not only on health knowledge, beliefs, and attitudes, but on behaviors as well, which can translate into major public health impact given the wide reach of mass media. Such impact can only be achieved, however, if principles of effective campaign design are carefully followed.
\end{abstract}

Mass media campaigns have long been a tool for promoting public health. Early examples in the United States include the Reverend Cotton Mather's campaign to promote inoculation for smallpox in the early 1700s and Dr. William Alcott and Reverend Sylvester Graham's healthy eating campaign in the early to mid 1800s. Using pamphlets and personal appeals, Mather was able to demonstrate that those who were not inoculated were much more likely to die from smallpox compared with those who were inoculated (Paisley, 2001). Using magazines, books, and booklets, as well as a health food store, Alcott and Graham (later known for the "graham cracker") promoted healthy eating and today hold a place in the history of vegetarianism (Iacobbo \& Iacobbo, 2005; Perloff, 2003).

More recently, Rogers and Storey (1987) chronicled the history of mass media campaigns in the United States, pointing out that the 1940s and 1950s were an era of minimal effects, when many large-scale campaign efforts failed and scholars hypothesized about why this was the case. The 1960s and 1970s ushered in a campaigns can succeed era, in which campaign successes, most notably the Stanford 3-city Heart Disease Prevention Program (SHDPP), brought new optimism to the 
campaign literature. Campaign scholars began to blame ineffective campaigns, rather than the recipients of those campaigns, for a lack of effects, and began to uncover and formalize principles of effective campaign design. The success and impact of the SHDPP has thus been described as "the most important single turning point in the rise of the health communication field" (Rogers, 1996, p. 16). Finally, the 1980s and 1990s have been described as a moderate effects era. As more was learned about campaigns, scholars came to have a new appreciation for how campaigns work, what makes them effective, and what their limits may be. While we have witnessed a greater accumulation of campaign successes in this era, campaign failures have still abounded (Rogers \& Storey, 1987).

So, where does that leave us in 2006 ? As will be argued in the current article, we currently find ourselves in an era that might be termed a conditional effects era, in which we have not necessarily discovered new principles of campaign design but rather have seen many of the principles that were formalized in previous eras effectively and creatively put into action. In fact, it will be argued that as campaign designers have increasingly attended to principles of effective campaign design, we have witnessed increasing health mass media campaign successes.

\section{Purpose of Current Article}

The purpose of the current article is threefold. First, I discuss the importance of health mass media campaigns and raise the question of whether they are truly capable of effectively impacting public health. Second, I review the health mass media campaign literature over the past 10 years and discuss what we have learned about the effectiveness of mass media campaigns in that period. Finally, I conclude with a discussion of possible avenues for the health campaign literature over the next 10 years. This article is in many ways an update to Rogers' (1996) report on health communication strategies that appeared in the very first issue of Journal of Health Communication.

\section{Mass Media Campaigns: An Effective Tool for Promoting Public Health?}

A compelling health communication intervention tool that potentially can address health attitude and behavioral change across numerous health problems and in numerous audiences is the mass media campaign. Rogers and Storey (1987) define a campaign as follows: "a campaign intends to generate specific outcomes or effects (2) in a relatively large number of individuals, (3) usually within a specified period of time, and (4) through an organized set of communication activities" (p. 821). What is the current practice of health mass media campaigns, and have they been found to be effective such that they are worth the investment of time, resources, and further study by communication scholars? Meta-analyses (research syntheses) of health mass media campaigns recently have emerged in the literature and two such projects provide answers to this critical question.

Snyder and Hamilton (2002). Snyder and Hamilton (2002) conducted what appears to be the first meta-analysis of the U.S. health mass media campaign literature. ${ }^{1}$ These researchers meta-analyzed a systematic sample of 48 health campaigns

${ }^{1}$ Although the current article encompasses a review of the campaign literature from 1996 forward, these meta-analyses examined literature from differing times frames, including 1974 1997 (Snyder \& Hamilton, 2002) and 1958-1998 (Derzon \& Lipsey, 2002). 
that were conducted in the United States and appeared in the published literature. Overall, they found a mean effect size representing the impact of health mass media campaigns on behavior to be $r=.09$. In percentage terms, the average campaign changed the behavior of about $8 \%$ of the population in the expected, positive direction.

In addition, Snyder and Hamilton (2002) found that (1) success varied with different behaviors, with seatbelt, oral health, and alcohol campaigns being the most successful; (2) greater effects were found for campaigns focused on adoption of new behaviors as compared with prevention or cessation of problem behaviors; and (3) greater effects were found in campaigns with greater reach/exposure. In addition, the strongest campaign effects were found with regard to campaigns that had a law enforcement aspect, such as seatbelt campaigns. When these enforcement campaigns are removed from the analysis, the overall effect of campaigns on behavior drops to $r=.05$.

Derzon and Lipsey (2002). A second meta-analysis of mass media campaigns appeared in the drug abuse prevention literature and was conducted by Derzon and Lipsey (2002). These researchers meta-analyzed 72 published and unpublished campaign studies that were designed to prevent or reduce youth substance use. Overall, they found a mean effect size representing the impact of media campaigns on behavior to be .04 standard deviations, and found impact on knowledge gain (.05) and positive attitude change (.02) as well.

In terms of moderators of the effects on behavior, campaigns utilizing radio, video, and television were found to have greater effects than those utilizing print media, and campaigns focused on alcohol use had more success than campaigns focused on illicit drugs or tobacco. Campaigns directed toward youth had little success, whereas those directed toward parents and retailers had more success. In addition, campaigns including certain types of messages were found to be particularly effective (e.g., stressing alternatives to drug use). Finally, campaigns with certain intervention characteristics such as supplementing media messages with other campaign components were found to have stronger effects than those without such characteristics.

Comment on Meta-Analyses. These meta-analytic projects are excellent contributions to the literature, as they are ambitious projects that provide an indication of the types of effects that average health campaigns produce. Certainly, the good news is that these meta-analyses suggest that campaigns to date have had actual impact not only on attitudes and knowledge, but on health behavior as well. Of course, by most standards these effects have been small.

In addition, we must consider some important caveats when interpreting these meta-analytic results. First, while the Derzon and Lipsey (2002) project included unpublished work, the Snyder and Hamilton (2002) project included only published work. Given academic journals' bias toward publishing significant findings, there is likely a publication bias (Rosenthal, 1991) in the group of studies included in the Snyder and Hamilton (2002) analysis. Thus, one could make the argument that if a number of failed campaign efforts were included in their analysis, then the actual effect size would be less than $r=.05$.

Further, the moderating influences examined in both meta-analyses, such as type of behavior, target audience, and so forth, are descriptive in nature. While such analyses generate important knowledge about the state of the literature, such moderators are not theoretical in nature. Thus, a crucial question that we ask here is the following: Did campaigns that followed effective campaign design principles (Atkin, 2001) have greater influence on knowledge, attitudes, and behavior? While Snyder 
and Hamilton (2002) did find evidence that greater exposure led to greater campaigns effects, other campaign design principles were not examined. If studies that follow campaign principles achieve greater effects, then among that group of studies the impact may be greater than the small overall effects reported here. While these meta-analyses did not examine this question, and it remains a high priority for future meta-analyses, evidence from selected recent primary studies does suggest that following effective campaign principles can lead to effects not only on attitudes, but on health behavior change as well (e.g., Farrelly et al., 2005; Hornik, 2002a; Palmgreen et al., 2001, 2005; Vaughan et al., 2000). And, these effects appear to be larger than the very small overall effects reported in the meta-analyses.

\section{Review of Campaign Literature: 1996-2005}

In the current article I suggest that the past 10 years of campaign research have not necessarily resulted in new campaign design principles. Rather, we have seen campaign design principles developed in previous eras effectively put into action in a number of impressive health mass media efforts. A number of scholars have summarized in detail the principles of effective campaign design, implementation, and evaluation (e.g., Atkin, 2001; Perloff, 2003; Randolph \& Viswanath, 2004; Rogers \& Storey, 1987; Salmon \& Atkin, 2003; Valente, 2001). Although an exhaustive list of all campaign principles is beyond the scope of the current article, Table 1 lists and defines some of the major principles of effective campaigns. ${ }^{2}$

Further, the literature review provided here will focus on how recent campaign efforts have used these principles effectively, and though the review is not meant to be exhaustive, it is meant to be relatively representative of the literature over the past 10 years. The literature collected for this review was published in a great variety of journals by individuals in numerous disciplines, and was about evenly split between U.S. and international campaigns. Evidence is indeed accumulating to support the proposition that mass media campaigns can be effective on the condition that principles of campaign design are attended to. Thus, I refer to the recent campaign literature as an era of conditional effects.

Formative Research. Formative research is extremely important to the design and implementation of a successful mass media campaign. Such research can enable campaign planners to truly understand their target audience in terms of the problem behavior at hand, their message preferences, and the most promising channels through which they can be reached (Atkin \& Freimuth, 2001; Valente, 2001). Mass media campaigns over the past 10 years have taken advantage of a variety of types of formative research to fulfill many of these purposes (see Table 2) using a variety of methods including analysis of archival data (e.g., Glik et al., 1998; Storey et al., 1999), survey work (e.g., Larsson et al., 2004; McDivitt et al., 1997), focus groups (e.g., Agha, 2003; Stead et al., 2005), and qualitative interviews (e.g., Witte et al., 1998; Wray et al., 2004). Few studies, however, reported using formative research to select campaign channels (e.g., Storey et al., 1999).

${ }^{2}$ Different authors highlight slightly different sets of principles of effective campaign design, although there is much overlap in this area as well. The current list of campaign principles is meant to be a representation of the major principles of effective campaign design, although sometimes others are discussed as well (see Randolph \& Viswanath, 2004; Rogers \& Storey, 1987). 
Table 1. Summary of major principles of effective campaign design applied to health mass media campaigns

Success is more likely when campaign designers...

Conduct formative research with the target audience to clearly understand the behavior and the problem area; pretest messages with target audience to be sure they are both appropriate and effective

Use theory as a conceptual foundation to the campaign; theory will suggest important determinants around which to develop messages, and will help ensure that campaign messages guide individuals through the process of attitude and/or behavior change

Segment audience into meaningful subgroups based on important characteristics such as demographic variables, risk characteristics, experience with the behavior, personality characteristics, and so forth

Use a message design approach that is targeted to and likely to be effective with the audience segment; develop novel and creative messages; design messages that will spark interpersonal discussions and may persuade individuals important to the target audience (e.g., influencers)

Place messages in channels widely viewed by the target audience; strategically position campaign messages within the selected channels

Conduct process evaluation including monitoring and collecting of data on implementation of campaign activities; ensure high message exposure among members of the target audience, including both reach and frequency

Use a sensitive outcome evaluation design that reduces threats to internal validity and permits firm causal conclusions about the campaign's influence on attitudes and behaviors to be made

As an example, Witte and colleagues (1998) conducted focus groups and qualitative interviews with a variety of at-risk groups in Kenya as part of the development of an HIV/AIDS prevention campaign, and used the extended parallel process model as a theoretical guide. These researchers found that formative research with campaign pamphlets and posters indicated that while perceived threat of HIV/AIDS AIDS was emphasized, important skills such as negotiating condom use as well as self and response efficacy for safer sex were neglected within the campaign materials. Thus, such feedback subsequently can be integrated into campaign messages and can greatly strengthen campaign materials.

Use of Theory. Use of theory as a guide to campaigns may be vital to campaign success. Theory can serve as a conceptual foundation for a campaign and can suggest important determinants upon which campaign messages might focus (e.g., Cappella et al., 2001; Noar, in press; Slater, 1999). Although one campaign review conducted through 1998 found mass media campaigns to generally not be theory based (Myhre \& Flora, 2000), Table 2 suggests that newer campaigns are increasingly utilizing theory. In addition, there has been great diversity in the theories being applied in this area, and many of the theories being used most often, including the theory of reasoned action, social cognitive theory, and the transtheoretical "stages of change" model, also are widely studied in the health behavior change literature (e.g., Noar \& Zimmerman, 2005). 
Table 2. Examples of major principles of effective campaign design in the health mass media campaign literature, 1996-2005

\section{Formative research}

- Help campaign designers to understand the nature of the problem behavior (e.g., Agha, 2003; Alstead et al., 1999; Comino et al., 1997; Doniger et al., 2001; McCombie et al., 2002; Oh et al., 2002; Palmgreen et al., 2001).

- Pretest message concepts and gain feedback regarding the appropriateness and effectiveness of messages with the target audience (e.g., Comino et al., 1997; Doniger et al., 2001; Hafstad \& Aaro, 1997; Kaiser Family Foundation, 2003; Kelder et al., 2000; McDivitt et al., 1997; Oh et al., 2002; Palmgreen et al., 2001; Reger et al., 2002; Stead et al., 2005; Witte et al., 1998; Wray et al., 2004)

Use of theory

- Diffusion of innovation (Larsson et al., 2004; Vaughan \& Rogers, 2000)

- Elaboration likelihood model (Reger et al., 2002)

- Extended parallel process model (Witte et al., 1998)

- Consumer information processing theory (Doniger et al., 2001)

- Media practice model (Oh et al., 2002)

- McGuire's hierarchy-of-effects model (Comino et al., 1997; Vaughan \& Rogers, 2000)

- Cognitive dissonance (Hafstad et al., 1996)

- Social norms theory (Thombs \& Hamilton, 2002)

- Social integration model (Thorson \& Beaudoin, 2004)

- Health belief model (Agha, 2003; Hill et al., 2002; Larsson et al., 2004)

- Theory of reasoned action (Booth-Butterfield \& Reger, 2004; Farrelly et al., 2002; Oh et al., 2002; Valente \& Saba, 2001; Worden \& Flynn, 2002)

- Theory of planned behavior (Reger et al., 2002; Stead et al., 2005)

- Social learning theory/social cognitive theory (Doniger et al., 2001; Kelder et al., 2000; McAlister et al., 2004; Vaughan \& Rogers, 2000; Worden \& Flynn, 2002)

- Transtheoretical model/stages of change model (McAlister et al., 2004; Meyer et al., 2003; Ratcliffe et al., 1997; Reger et al., 2002; Renger et al., 2002; Vaughan \& Rogers, 2000; Willemson et al., 1998)

Audience segmentation

- Numerous studies segment on demographic variables including gender, race, and age group, as well as on behavioral characteristics.

- In addition, segmentation conducted on variables including socioeconomic status (McDivitt et al., 1997), language (Bauman et al., 2001; Kelder et al., 2000; McAlister et al., 2000), theoretical characteristics (Korhonen et al., 1998; Miller et al., 2000; Renger et al., 2002; Roccella, 2002; Vaughan \& Rogers, 2000), and personality characteristics such as sensation seeking (Palmgreen et al., 2001, 2005)

Message design and targeting

- Entertainment education (Boulay et al., 2002; Glik et al., 1998; Kaiser Family Foundation, 2003, 2004; Mohammed, 2001; Storey et al., 1999; Vaughan \& Rogers, 2000; Vaughan et al., 2000)

- Sensation-seeking targeting (Palmgreen et al., 2001, 2005)

- Hard-hitting messages designed for youth "on the cutting edge of trends" (Farrelly et al., 2002) 
- "Tobacco industry manipulation" strategy (Sly et al., 2001b)

- ONDCP strategy, which includes a focus on short-term negative consequences of drug use (Kelder et al., 2000; Palmgreen et al., 2005)

- Targeting to additional audiences (interpersonal influencers) such as health professionals including doctors (Comino et al., 1997; Dixon et al., 1998; Korhonen et al., 1998; Larsson et al., 2004; Pierce et al., 2002; Reger et al., 2002), parents (Kelder et al., 2000), and retailers (Dixon et al., 1998)

Channel selection

- Televised media including short films, public service announcements, press coverage, and other spots (PSAs; Agha, 2003; Bauman et al., 2001; Comino et al., 1997; Dixon et al., 1998; Doniger et al., 2001; Farrelly et al., 2002; Hafstad \& Aaro, 1997; Hill et al., 2002; Kaiser Family Foundation, 2003, 2004; Kelder et al., 2000; Kincaid et al., 2002; McAlister et al., 2004;

McCombie et al., 2002; McDivitt et al., 1997; Miller et al., 2003;

Moreau et al., 2002; Oh et al., 2002; Owen, 2000; Palmgreen et al., 2001;

Pierce et al., 2002; Ratcliffe et al., 1997; Reger et al., 2000, 2002;

Renger et al., 2002; Secker-Walker et al., 1997; Siegel \& Biener, 2000;

Sly et al., 2001a, 2001b; Stead et al., 2005; Tambashe et al., 2003;

Tamir et al., 2001; Thorson \& Beaudoin, 2004; Trussell et al., 2001;

Valente \& Saba, 2001; Wimbush et al., 1998; Williams et al., 2002;

Worden \& Flynn, 2002; Zimicki et al., 2002)

- Radio and other audio spots (Alstead et al., 1999; Boulay et al., 2002; Connell et al., 2001; Dixon et al., 1998; Doniger et al., 2001; Hill et al., 2002; Kaiser Family Foundation, 2004; Kincaid et al., 2002; McAlister et al., 2004; McCombie et al., 2002; McDivitt et al., 1997; Meyer et al., 2003; Mizuno et al., 2002; Mohammed, 2001; Moreau et al., 2002; Oh et al., 2002; Owen, 2000; Pierce et al., 2002; Reger et al., 2000, 2002; Secker-Walker et al., 1997; Siegel \& Biener, 2000; Storey et al., 1999; Surkan et al., 2003; Tambashe et al., 2003; Trussell et al., 2001; Valente \& Saba, 2001; Vaughan \& Rogers, 2000; Vaughan et al., 2000; Williams et al., 2002; Worden \& Flynn, 2002; Wray et al., 2004; Zimicki et al., 2002)

- Print media (e.g., newspapers, magazines; Bauman et al., 2001; Dixon et al., 1998; Farrelly et al., 2002; Hafstad \& Aaro, 1997; Hafstad et al., 1996; Hill et al., 2002; Larsson et al., 2004; Kincaid et al., 2002; McAlister et al., 2004; Miller et al., 2000; Nishtar et al., 2004; Owen, 2000; Pierce et al., 2002; Reger et al., 2002; Siegel \& Biener, 2000; Storey et al., 1999; Thombs \& Hamilton, 2002; Thorson \& Beaudoin, 2004; Trussell et al., 2001; Valente \& Saba, 2001; Williams et al., 2002; Zimicki et al., 2002)

- Community-based activities including mobilization, community events, workshops, peer education, and public relations activities (Alstead et al., 1999; Bauman et al., 2001; Boulay et al., 2002; Comino et al., 1997; Hill et al., 2002; Kaiser Family Foundation, 2003, 2004; Kelder et al., 2000; Kincaid et al., 2002; Korhonen et al., 1998; McAlister et al., 2004; Miller et al., 2000; Reger et al., 2000, 2002; Stead et al., 2005; Storey et al., 1999; Tambashe et al., 2003; Trussell et al., 2001) 
- Posters and/or leaflets (Alstead et al., 1999; Andersen et al., 2001;

Dixon et al., 1998; Kaiser Family Foundation, 2004; Korhonen et al., 1998; Larsson et al., 2004; Mizuno et al., 2002; Moreau et al., 2002;

Ratcliffe et al., 1997; Renger et al., 2002; Siegel \& Biener, 2000;

Thombs \& Hamilton, 2002; Witte et al., 1998; Zimicki et al., 2002)

- Billboards and/or bus signs (Alstead et al., 1999; McAlister et al., 2004; Pierce et al., 2002; Siegel \& Biener, 2000; Tambashe et al., 2003; Thombs \& Hamilton, 2002)

- Toll-free hotlines (Bauman et al., 2001; Kaiser Family Foundation, 2003, 2004; McAlister et al., 2004; Miller et al., 2003; Mizuno et al., 2002;

Oh et al., 2002; Owen, 2000; Ratcliffe et al., 1997; Trussell et al., 2001; Wimbush et al., 1998)

- Internet websites (Andersen et al., 2001; Farrelly et al., 2002; Kaiser Family Foundation, 2003, 2004; Kelder et al., 2000; Larsson et al., 2004; Reger et al., 2002; Trussell et al., 2001)

- School-based components (Hill et al., 2002; McAlister et al., 2004; McCombie et al., 2002; Secker-Walker et al., 1997; Tamir et al., 2001; Worden \& Flynn, 2002)

- Work-site programs (Reger et al., 2002; Willemsen et al., 1998), take-home audio tapes (Connell et al., 2001), direct mail coupons (Meyer et al., 2003), cookbooks and recipe cards (Dixon et al., 1998), merchandise such as t-shirts, hats, mugs, dog tags, temporary tattoos, stickers, inserts in CDs (Bauman et al., 2001; Farrelly et al., 2002; Kaiser Family Foundation, 2003; Mizuno et al., 2002; Witte et al., 1998; Zimicki et al., 2002)

- Policy changes to encourage behavior change including law enforcement for seat belt use (Williams et al., 2002) and cigarette tax increases (Siegel \& Biener, 2000)

- Materials intended to help foster behavior change including condom packets and sexually transmitted disease test kits (Andersen et al., 2001; Mizuno et al., 2002; Oh et al., 2002)

Process evaluation and message exposure

- Exposure reported as high as 69\% (Thombs \& Hamilton, 2002), 70\% (Dixon et al., 1998; McCombie et al., 2002; Wimbush et al., 1998), 73\% (Alstead et al., 1999), 75\% (Farrelly et al., 2002; Vaughan et al., 2000), 77\% (Tamir et al., 2001), 84\% (Pierce et al., 2002), 85\% (Tambashe et al., 2003), 94\% (Kaiser Family Foundation, 2004), and $95 \%$ (Palmgreen et al., 2001)

Outcome evaluation

- Tracking callers to a hotline (Miller et al., 2003; Oh et al., 2002; Owen, 2000)

- One time, post-only survey (Agha, 2003; Hafstad \& Aaro, 1997; Hafstad et al., 1996; Mizuno et al., 2002; Moreau et al., 2002; Nishtar et al., 2004; Renger et al., 2002; Sly et al., 2002; Stead et al., 2005; Surkan et al., 2003; Tambashe et al., 2003; Tamir et al., 2001; Thombs \& Hamilton, 2002)

- Multiple postcampaign surveys (Dixon et al., 1998; Mizuno et al., 2002; Tamir et al., 2001) 
- One-group Pretest/post-test designs, which sometimes include additional posttests (Alstead et al., 1999; Booth-Butterfield \& Reger, 2004; Comino et al., 1997; Connell et al., 2001; de Walle et al., 1999; Doniger et al., 2001; Farrelly et al., 2005; Hill et al., 2002; Kaiser Family Foundation, 2003; McAlister et al., 2004; McCombie et al., 2002; McDivitt et al., 1997; Ratcliffe et al., 1997; Renger et al., 2002; Siegel \& Biener, 2000; Sly et al., 2001a, 2001b; Stead et al., 2005; Storey et al ., 1999; Tambashe et al., 2003; Thorson \& Beaudoin, 2004; Trussell et al., 2001; Valente \& Saba, 2001; Wimbush et al., 1998; Wray et al., 2004; Zimicki et al., 2002)

- Pretest/post-test control group designs (Bauman et al., 2001; Connell et al., 2001; Larsson et al., 2004; Miller et al., 2000; Pierce et al., 2002; Reger et al., 1999, 2000, 2002; Vaughan \& Rogers, 2000;

Vaughan et al., 2000; Willemsen et al., 1998)

- Post-test-only control group designs (Meyer et al., 2003; Mohammed, 2001)

- Time series designs (Kincaid et al., 2002; Korhonen et al., 1998; Miller et al., 2003; Palmgreen et al., 2001, 2005; Pierce et al., 2002; Williams et al., 2002; Worden \& Flynn, 2002)

Audience Segmentation. Audience segmentation is another important campaign design principle and has been described in the following manner: "The basic idea of segmentation is simple: divide a population, market, or audience into groups whose members are more like each other than members of other segments" (Grunig, 1989, p. 202). The ultimate purpose of segmentation is to create homogeneous groups whose message preferences are similar to one another so that campaign messages can be designed to be maximally effective with the target audience (Atkin, 2001; Slater, 1996). Further, a lack of segmentation and message targeting are thought to be major factors that contributed to failed campaigns of the past (Flay \& Sobel, 1983; Myhre \& Flora, 2000; Zimmerman et al., in press).

Numerous campaigns over the past 10 years have segmented on a variety of variables, including gender (e.g., Hafstad et al., 1996), race (e.g., Farrelly et al., 2002), age group (e.g., Mizuno et al., 2002), and behavioral characteristics (e.g., Agha, 2003; Kelder et al., 2000). In addition, studies have segmented on a number of other characteristics (see Table 2), and in practice campaigns often use multiple variables upon which to segment audiences (Slater, 1996). For instance, after deciding to focus on youth, a number of campaigns have segmented in order to target those "at-risk," defining this as "cutting edge" youth (Farrelly et al., 2002, 2005), high sensation seekers (Palmgreen et al., 2001), youth who are occasional drug or nondrug users and have particular risk attributes (Kelder et al., 2000; Palmgreen et al., 2005), or African American youth (Kaiser Family Foundation, 2004). Further, each of these projects resulted in an effective campaign, suggesting that the segmentation and subsequent message targeting was successful.

Message Design and Targeting. Once groups are segmented and it is clear who the target audience is, how can campaign designers create persuasive messages that have maximal impact? A number of unique and creative message design strategies have been utilized over the past 10 years (see Table 2). For instance, the antismoking Truth 
campaign was designed for youth "on the cutting edge of trends" with a "tobacco industry manipulation" strategy (Farrelly et al., 2002; Sly et al., 2001b). The messages in this campaign focused on the tobacco industry's manipulative marketing practices and cover-ups, taking advantage of the unique historical context of the Master Settlement Agreement in the United States (see Farrelly et al., 2005). Palmgreen and colleagues' (2001) sensation-seeking targeting approach, which segments audiences and subsequently designs messages to be effective with high sensation-seekers, suggests designing messages that have characteristics including drama, intensity, novelty, emotion, a lack of preaching, and a fast pace (Palmgreen \& Donohew, 2003). The Office of National Drug Control Policy's (ONDCP) antidrug campaign developed a unique theory-based message design strategy focused on short-term consequences of drug use; use of humor, sensation, and novelty; avoidance of preaching; and positive role models (Kelder et al., 2000). Finally, a number of unique applications of entertainment education (Singhal \& Rogers, 2003) have recently appeared in this literature, including radio soap operas (Vaughan et al., 2000) and health-related storylines in popular television shows (Glik et al., 1998). Further, in addition to focusing on the target audience, some campaigns have targeted messages to so-called interpersonal influencers in order to increase the chances of campaign success (see Table 2).

Channel Selection. No matter how persuasive one's campaign messages are, they cannot be effective without being placed in channels with great potential to reach the target audience (Salmon \& Atkin, 2003). Table 2 reveals that television has been a very popular choice for campaign designers, as have radio and print media. Further, this review reveals great diversity among a number of other channels and methods that campaigns have used to "get their message out." Surprisingly, few mass media campaigns have used media only, and rather most campaigns have used a number of varied channels. From a scientific point of view, if a campaign utilizing numerous channels is effective, it can be difficult or impossible to know which component(s) were most important to campaign effects. On the other hand, synergy among campaign components can likely increase exposure and may increase the impact of a campaign (Derzon \& Lipsey, 2002).

Process Evaluation and Message Exposure. Process evaluation is concerned with the monitoring and collection of data on fidelity and implementation of campaign activities (e.g., Valente, 2001). Such data can improve the execution of campaigns and can inform campaign planners as to why certain outcomes of a campaign were or were not achieved. While a few articles in the current review discussed process evaluation in detail (e.g., Meyer et al., 2003; Renger et al., 2002; Willemsen et al., 1998; Witte et al., 1998), most said little about it beyond the reporting of campaign exposures rates. This may be related to the fact that these campaign articles spent most of their time focused on outcome evaluation and had little space to devote to process data.

Related to process evaluation, a key goal of campaigns is the achievement of maximal message exposure. Recent data indicate, however, that the goal of widespread campaign exposure sought by campaign designers often is not met. In fact, Snyder and Hamilton (2002) found average campaigns to have only $36 \%-42 \%$ reach. In contrast to this, Table 2 reveals that a number of recent campaigns have demonstrated excellent exposure rates. These campaigns apparently have achieved this through saturation of targeted campaign messages in channels widely viewed by the audience segment. Of course, both reach and frequency have been found to be important to campaign success (Derzon \& Lipsey, 2002; Snyder \& Hamilton, 
2002), and because $95 \%$ of an audience was reached does not mean that the frequency of exposure was enough to influence them. A number of campaigns over the past 10 years have demonstrated that high reach is possible, though, and some have achieved high frequency as well.

Outcome Evaluation. In terms of evaluation, Table 2 reveals that health mass media campaigns over the past 10 years have been evaluated in a number of ways. Although random assignment to conditions often is not possible and thus quasiexperimental designs tend to be necessary, what is troubling is that many campaigns have used weak designs. For instance, numerous campaigns use a one time, postonly survey or a one-group pretest-post-test design as their sole evaluation tool. One only needs to go as far as the basic research design literature to realize that such designs do not control for a number of threats to internal validity (Campbell \& Stanley, 1963). Although campaigns often do not lend themselves to "gold standard" designs such as randomized controlled trials (Hornik, 2002b), designs such as these simply cannot provide conclusive evidence that health mass media campaigns work. Surprisingly, nearly all of the campaigns using the one time, post-only survey design were funded efforts. ${ }^{3}$ Thus, we can only speculate that either (1) the funds were not adequate to increase the rigor of the designs, or (2) the researchers were not aware of the significant weaknesses with this design or were aware but simply viewed it as an acceptable research design in this literature.

A bright spot in the recent literature however, are the more rigorous designs that have been applied successfully to campaigns. Time series designs and pretest-posttest control-group designs often are flexible enough to be implemented in large-scale field trials, but they are much more rigorous in that they control for most threats to internal validity (Campbell \& Stanley, 1963). Time series designs have the unique advantage of demonstrating the secular trends with regard to attitudes or behaviors before a campaign takes place. In fact, such studies often have demonstrated that secular trends direct behavior in either a negative direction (making it difficult to achieve positive campaign effects) or a positive direction (in which case the campaign may not be able to outperform the secular trend; e.g., Fan, 2002; Kincaid et al., 2002; Palmgreen et al., 2001, 2005). While time series designs are quite strong, pretestpost-test control group designs are likely to be more cost effective and can yield meaningful data, sometimes illuminating a secular trend as well (e.g., Miller et al., 2000).

\section{Future Directions: Where Might the Campaign Literature Progress Over the Next 10 Years?}

In the following section, I comment on selected issues related to trends in the literature over the past 10 years and suggest some future avenues for research in the health mass media campaign area (see Table 3).

${ }^{3}$ Campaigns also were examined in order to see if they were designed and evaluated by practitioners or by academics. One might hypothesize that there would be differences in outcome evaluation design or other factors in practitioners' campaigns as compared with campaigns developed and evaluated by academics in a research setting, where resources are sometimes more plentiful. Unfortunately, this was difficult, if not impossible, to determine from the information provided in the articles. 
Table 3. Suggestions for future focal areas and research activities in the health mass media campaign area

Area Suggestion

General

Theory

Message design and development
- Perform meta-analyses of campaign literature examining effective campaign principles as moderator variables

- Continue to build the empirical evidence base through both meta-analysis and primary studies of the impact of well-designed campaigns on campaign outcomes.

- Pay greater attention to the role of potentially important factors not contained in the principles to the success of campaigns.

- Develop and disseminate a template for standardized reporting of mass media campaign evaluations for journal articles, which includes reporting of which principles were attended to, why, and how

- Renew dialogue regarding the role of theory in mass media campaigns

- Develop communication-based campaign theories

- Conduct analyses to help understand if theoretical variables mediate campaign outcomes

- Discuss implications of campaign findings for theory development

- Develop and formalize new, creative, and innovative message design approaches

- Disseminate and share message design approaches with those in other disciplines

- Collaborate with those in advertising and social marketing on message design approaches to foster increased ingenuity and creativity in this area

- Report more fully on message design strategies in campaign articles

- Develop and test message design approaches that encourage interpersonal communication

- Continue to evaluate the role of interpersonal communication and social networks with regard to campaign effects

- Continue research efforts on the effectiveness of interactive health communication and synergistic approaches combining new and mass media 
Table 3. Continued

Area

Suggestion

Evaluation

Replication and dissemination

- Conduct process evaluation of campaigns and report such activities in evaluation articles

- Conduct more campaigns with rigorous research designs to continue to build the empirical evidence base of campaign effects on health behavior

- Consider how weaker research designs can be improved in the context of real-world field trials (see Hornik, 2002c)

- Conduct studies comparing how different research designs may lead to different conclusions about campaign effects

- Consider replication and dissemination issues when designing campaign efforts

- Conduct more studies on 1-2 channel efforts that attempt to effect health behavior change

- Conduct more carefully controlled studies that are capable of parsing out the effects of individual channels on health behavior change (e.g., Worden \& Flynn, 2002)

\section{Theoretical Advances}

Health mass media campaigns over the past 10 years have taken greater advantage of a variety of theories, and this is a positive development. Differing theories can play differing roles, however, in campaign development and evaluation. For instance, while many theories suggest determinants to focus on with campaign messages, some theories also provide intervention strategies (e.g., social cognitive theory) or even implications for audience segmentation (e.g., stages of change). However, when developing campaigns, what is the role that we want theory to play? Campaign designers should choose carefully among existing theories when planning campaigns, as differing theories have differing implications (e.g., Noar, in press). In addition, most of the theories in Table 2 were developed in disciplines other than communication for applications other than mass media campaigns. Campaign scholars may want to consider the possibility of developing new message-based theories that help us better understand communication processes in the context of campaigns, along the lines of Witte's (1992) extended parallel process model. Although behavioral theories, many of which are used by campaign designers, abound in the literature (e.g., Noar \& Zimmerman, 2005), there are far fewer communication-oriented theories that focus on how to create messages based on theoretical determinants as well as how different types of individuals respond to such messages.

Further, the choice of theory should carry through to evaluation, and thus theoretical determinants that were targeted in campaign messages (e.g., attitudes, self-efficacy) should be measured and evaluated for change. Mediational analyses (for instance, examining whether a change in attitudes was responsible for a 
behavioral change produced by a campaign) can help uncover whether it was the hypothesized theoretical determinants that played a role in health behavior change (e.g., Baron \& Kenny, 1986; MacKinnon et al., 2002). These kinds of analyses have not been widely conducted in the health intervention literature even though they have the potential to help move the science of health behavior change forward (Baranowski et al., 1998; Michie \& Abraham, 2004). Further, the potential of intervention findings including those from mass media campaigns to come full circle and inform changes to theoretical models has much potential (see Rothman, 2004).

\section{Message Design and Development}

A number of interesting and effective message design strategies have appeared in the literature over the past 10 years, and this trend will likely continue. Counterbalancing this is the fact that message design was not addressed in many of the published studies examined here, however, and Table 2 suggests that only a limited number of formalized message design approaches are appearing in this literature. While communication scholars are well aware of message design principles and theories, those from other disciplines may be less aware of such approaches. In addition to better dissemination of message design frameworks and theories, campaign scholars should strive for continued innovation in this area. For instance, communication scholars might collaborate with those in advertising and social marketing who have significant experience developing messages and in that manner develop new and creative approaches to message design (e.g., Evans et al., 2002; Zimmerman et al., in press). Finally, much of the work conducted in this area may not be fully reported in evaluation articles, even though such reporting would be useful.

In addition, there now appears to be evidence to support the position that individuals are changed more by discussions of campaign messages than by the direct effects of viewing such messages (e.g., Hornik, 2002d). In fact, campaign messages that spark interpersonal exchange and dialogue among the target audience may increase both the reach and impact of a campaign (Boulay et al., 2002; Hafstad \& Aaro, 1997; Hafstad et al., 1996; Moreau et al., 2002). Thus, an obvious implication for message designers is to find ways to encourage dialogue about the health issue among members of the target audience. Such an approach may be different from creating messages to influence individuals directly, and some message design approaches may lend themselves well to such an orientation (e.g., entertainment education).

Finally, a trend that will most definitely continue is increased investment in interactive health communication technology (e.g., Street, Gold, \& Manning, 1997; see Suggs article, this volume). Table 2 revealed that a number of recent campaigns utilized websites. However, how does an ideal mass media campaign utilize the Internet? Should some campaign efforts be completely devoted to driving individuals to a website, where an interactive intervention could be delivered? While there is much excitement about interactive technology, much more evidence about its effectiveness by itself and in conjunction with mass media campaigns is needed (e.g., Noar, Clark, Cole, \& Lustria, in press; Street et al., 1997).

\section{Evaluation of Campaigns}

Other than data on exposure, it appears that reporting on process evaluation has been rare in the literature over the past 10 years. If a campaign fails, and process evaluation 
has not been conducted, it will be difficult to understand why this was the case. Thus, future campaign efforts should make use of process evaluation and should report the results of such evaluation, with at least some minimal level of detail.

While many studies over the past 10 years have used relatively weak outcome evaluation designs, a number have used strong designs that have provided evidence of attitude and behavior change, and this trend is likely to continue. Those involved in campaigns should continue to strive for the most rigorous research designs possible, as these will generate the best evidence of campaign effectiveness. In fact, note that in Hornik's (2002a) collection of campaign studies "with evidence of behavior change" there is a notable absence of studies using the post-only survey design, which is only capable of providing weak evidence of effectiveness.

There may be cases, however, in which a strong research design is simply not possible. For instance, strong research designs including time series and control group designs are much more expensive to implement than are the weaker designs discussed here. Left to choose between a strong campaign with a weak evaluation design or a weak campaign with a strong evaluation design, the campaign designer may choose the former. When barriers including lack of funding impede the implementation of a strong design, one can incorporate recommendations for increasing rigor with weaker designs (see Hornik, 2002c). It must be recognized, however, that while some of the weaker designs may offer evidence of exposure and clues regarding campaign effectiveness, they cannot provide solid evidence of campaign effectiveness and likely will contribute little to the scientific literature on effectiveness.

\section{Replication and Dissemination}

The ultimate goal of health mass media campaigns in the literature is to provide evidence of what works, to be able to disseminate it to populations at risk. Many of the campaigns in this literature, however, have not only used multiple mass media channels, but numerous nonmedia components as well (see Table 2). In fact, some campaigns in the current review had as many as 12 components (e.g., Miller et al., 2000), and could be criticized as using a "kitchen sink" approach. The issue here is that if the campaign works, from a scientific point of view we will have learned little, as unpacking which components led to success post hoc is difficult. In addition, a 12-channel intervention is much more difficult to replicate and disseminate than is a 1- or 2-channel intervention.

Historically, it has been questioned whether mass media campaigns alone can change behavior (Rogers \& Storey, 1987; Wallack, 1981). Thus, multiple channels and components have been suggested in order to increase one's chances of success. Recent well-executed studies suggest, however, that mass media campaigns consisting solely of media such as television or radio can be effective in changing health behavior (e.g., Palmgreen et al., 2001, 2005; Reger et al., 1999; Worden \& Flynn, 2002). Thus, at this juncture in the literature we should question the advice that "more is better" when it comes to campaign channels.

\section{Conclusion}

Although this article argues that fidelity to principles of campaign design is the most important factor to the success of a mass media campaign, it must be acknowledged 
that other factors also may be important. For instance, meta-analyses have clearly demonstrated that the choice of which behavior one is intervening with will impact the chances of campaigns success, and other factors not routinely considered by campaign evaluators also may affect campaign results (e.g., conducting a campaign in a small versus large community). In fact, even standard campaigns from the "classic" media campaign literature vary on a number of dimensions (see Salmon \& Atkin, 2003), many of which are not often studied but which could impact campaign effectiveness. Thus, at the outset, campaigns vary in numerous ways and some efforts may start out in an advantaged or a disadvantaged position. In addition, although priority level of the principles was not discussed, it is likely that some principles are more important than others, and that ignoring one crucial principle can doom a campaign (e.g., low exposure). Thus, the threshold for developing, implementing, and evaluating a successful mass media campaign remains high, and there are still numerous ways in which campaigns can fail (see Smith, 2002).

With the above caveat in mind, the literature is beginning to amass evidence that targeted, well-executed health mass media campaigns can have small-to-moderate effects not only on health knowledge, beliefs, and attitudes, but on behaviors as well. Given the wide reach that mass media is capable of, a campaign with a small-tomoderate effect size that reaches thousands of people will have a greater impact on public health than would an individual or group-level intervention with a large effect size that only reaches a small number of people (see Glasgow, 2002). Thus, large-scale health campaign efforts can be successful in achieving broad public health impact among communities in the United States and across the world, making further inquiry as to the best means to achieve this impact a worthy venture (see Table 3).

\section{References}

Agha, S. (2003). The impact of a mass media campaign on personal risk perception, perceived self-efficacy and on other behavioral predictors. AIDS Care, 15(6), 749-762.

Alstead, M., Campsmith, M., Halley, C. S., Hartfield, K., Goldbaum, G., \& Wood, R. W. (1999). Developing, implementing, and evaluating a condom promotion program targeting sexually active adolescents. AIDS Education and Prevention, 11(6), 497-512.

Andersen, B., Ostergaard, L., Moller, J. K., \& Olesen, F. (2001). Effectiveness of a mass media campaign to recruit young adults for testing of Chlamydia trachomatis by use of home obtained and mailed samples. Sexually Transmitted Infections, 77(6), 416-418.

Atkin, C. K. (2001). Theory and principles of media health campaigns. In R. E. Rice \& C. K. Atkin (Eds.), Public communication campaigns (3rd ed., pp. 49-68). Thousand Oaks, CA: Sage.

Atkin, C. K. \& Freimuth, V. S. (2001). Formative evaluation research in campaign design. In R. E. Rice \& C. K. Atkin (Eds.), Public communication campaigns (3rd ed., pp. 125-145). Thousand Oaks, CA: Sage.

Baranowski, T., Anderson, C., \& Carmack, C. (1998). Mediating variable framework in physical activity interventions: How are we doing? How might we do better? American Journal of Preventive Medicine, 15(4), 266-297.

Baron, R. M. \& Kenny, E. A. (1986). The moderator-mediator variable distinction in social psychological research: Conceptual, strategic, and statistical considerations. Journal of Personality and Social Psychology, 51(6), 1173-1182.

Bauman, A. E., Bellew, B., Owen, N., \& Vita, P. (2001). Impact of an Australian mass media campaign targeting physical activity in 1998. American Journal of Preventive Medicine, $21(1), 41-47$. 
Booth-Butterfield, S. \& Reger, B. (2004). The message changes belief and the rest is theory: The " $1 \%$ or less" milk campaign and reasoned action. Preventive Medicine, 39(3), 581-588.

Boulay, M., Storey, J. D., \& Sood, S. (2002). Indirect exposure to a family planning mass media campaign in Nepal. Journal of Health Communication, 7(5), 379-399.

Campbell, D. T. \& Stanley, J. C. (1963). Experimental and quasi-experimental designs for research. Boston: Houghton Mifflin.

Cappella, J. N., Fishbein, M., Hornik, R., Ahern, R. K., \& Sayeed, S. (2001). Using theory to select messages in antidrug media campaigns: Reasoned action and media priming. In R. E. Rice \& C. K. Atkin (Eds.), Public communication campaigns (3rd ed., pp. 214 230). Thousand Oaks, CA: Sage.

Comino, E. J., Bauman, A., Mitchell, C. A., Ruffin, R. E., Antic, R., Zimmerman, P. V., \& Gutch, R. C. (1997). The Australian national asthma campaign: Effects of public education activities based on mass media. American Journal of Preventive Medicine, 13(4), 251-256.

Connell, D., Goldberg, J. P., \& Folta, S. C. (2001). An intervention to increase fruit and vegetable consumption using audio communications. Journal of Health Communication, $6(1), 31-43$.

de Walle, H. E. K., van der Pal, K. M., de Jong-van den Berg, L. T. W., Jeeninga, W., Schouten, J. S., de Rover, C. M., Buitendijk, S. E., \& Cornel, M. C. (1999). Effect of mass media campaign to reduce socioeconomic differences in women's awareness and behaviour concerning use of folic acid: Cross sectional study. British Medical Journal, 319, 291-292.

Derzon, J. H. \& Lipsey, M. W. (2002). A meta-analysis of the effectiveness of mass-communication for changing substance-use knowledge, attitudes, and behavior. In W. D. Crano \& M. Burgoon (Eds.), Mass media and drug prevention: Classic and contemporary theories and research (pp. 231-258). Mahwah, NJ: Erlbaum.

Dixon, H., Borland, R., Segan, C., Stafford, H., \& Sindall, C. (1998). Public reaction to Victoria's "2 fruit n' 5 veg every day" campaign and reported consumption of fruit and vegetables. Preventive Medicine, 27(4), 572-582.

Doniger, A. S., Adams, E., Utter, C. A., \& Riley, J. S. (2001). Impact evaluation of the "not me, not now" abstinence-oriented, adolescent pregnancy prevention communications program, Monroe County, New York. Journal of Health Communication, 6(1), 45-60.

Evans, W. D., Wasserman, J., Bertolotti, E., \& Martino, S. (2002). Branding behavior: The strategy behind the Truth campaign. Social Marketing Quarterly, 8(3), 17-29.

Fan, D. P. (2002). Impact of persuasive information on secular trends in health-related behaviors. In R. C. Hornik (Ed.), Public health communication: Evidence for behavior change (pp. 251-264). Mahwah, NJ: Lawrence Erlbaum.

Farrelly, M. C., Davis, K. C., Havilan, M. L., Messeri, P., \& Healton, C. G. (2005). Evidence of a dose-response relationship between "truth" antismoking ads and youth smoking prevalence. American Journal of Public Health, 95(3), 425-431.

Farrelly, M. C., Healton, C. G., Davis, K. C., Messeri, P., Hersey, J. C., \& Haviland, M. L. (2002). Getting to the truth: Evaluating national tobacco countermarketing campaigns. American Journal of Public Health, 92(6), 901-907.

Flay, B. R. \& Sobel, J. L. (1983). The role of mass media in preventing adolescent substance abuse. In T. J. Glynn, C. G. Leukefeld, \& J. P. Lundford (Eds.), Preventing Adolescent Drug Abuse: Intervention Strategies. NIDA Research Monograph Series (47).

Glasgow, R. E. (2002). Evaluation of theory-based interventions: The RE-AIM model. In K. Glanz, F. M. Lewis, \& B. K. Rimer (Eds.), Health behavior and health education: Theory, research, and practice (3rd ed., pp. 531-544). San Francisco, CA: John Wiley \& Sons.

Glik, D., Berkanovic, E., Stone, K., Ibarra, L., Jones, M. C., Rosen, B., Schreibman, M., Gordon, L., Minassian, L., \& Richardes, D. (1998). Health education goes Hollywood: Working with prime-time and daytime entertainment television for immunization promotion. Journal of Health Communication, 3(3), 263-283. 
Grunig, J. (1989). Publics, audiences, and market segments: Segmentation principles for campaigns. In C. Salmon (Ed.), Information campaigns: Balancing social values and social change (pp. 199-228). Newbury Park, CA: Sage.

Hafstad, A. \& Aaro, L. E. (1997). Activating interpersonal influence through provocative appeals: Evaluation of a mass media-based antismoking campaign targeting adolescents. Health Communication, 9(3), 253-272.

Hafstad, A., Aaro, L. E., \& Langmark, F. (1996). Evaluation of an antismoking mass media campaign targeting adolescents: The role of affective responses and interpersonal communication. Health Education Research, 11(1), 29-38.

Hill, D., White, V., Marks, R., \& Borland, R. (2002). Changes in sun-related attitudes and behaviors, and reduced sunburn prevalence in a population at high risk of melanoma. In R. C. Hornik (Ed.), Public health communication: Evidence for behavior change (pp. 163-178). Mahwah, NJ: Lawrence Erlbaum.

Hornik, R. C. (Ed.) (2002a). Public health communication: Evidence for behavior change. Hillsdale, NJ: Lawrence Erlbaum.

Hornik, R. C. (2002b). Public health communication: Making sense of contradictory evidence. In R. C. Hornik (Ed.), Public health communication: Evidence for behavior change (pp. 1-22). Mahwah, NJ: Lawrence Erlbaum.

Hornik, R. C. (2002c). Epilogue: Evaluation design for public health communication programs. In R. C. Hornik (Ed.), Public health communication: Evidence for behavior change. (p. 385-405). Mahwah, NJ: Lawrence Erlbaum.

Hornik, R. C. (2002d). Exposure: Theory and evidence about all the ways it matters. Social Marketing Quarterly, 8(3), 31-37.

Iacobbo, K. \& Iacobbo, M. (2005, June 15). Christian roots of vegetarianism. Retrieved June 15,2005 , from http://www.vegsource.com/veghistory/christian_roots_print.htm

Kaiser Family Foundation. (2003). Reaching the MTV generation: Recent research on the impact of the Kaiser Family Foundation/MTV Public Education Campaign on Sexual Health. Menlo Park, CA: Author.

Kaiser Family Foundation. (2004). Assessing public education programming on HIV/AIDS: A national survey of African Americans. Menlo Park, CA: Author.

Kelder, S. H., Maibach, E., Worden, J. K., Biglan, A., \& Levitt, A. (2000). Planning and initiation of the ONDCP national youth anti-drug media campaign. Journal of Public Health Management Practice, 6(3), 14-26.

Kincaid, D. L., Merritt, A. P., Nickerson, L., Buffington, S. C., de Castro, M. P., \& de Castro, B. M. (2002). Impact of a mass media vasectomy promotion campaign in Brazil. In R. C. Hornik (Ed.), Public health communication: Evidence for behavior change (pp. 179-196). Mahwah, NJ: Lawrence Erlbaum.

Korhonen, T., Uutela, A., Korhonen, H. J., \& Puska, P. (1998). Impact of mass media and interpersonal health communication on smoking cessation attempts: A study in North Karelia, 1989-1996. Journal of Health Communication, 3(2), 105-119.

Larsson, M., Eurenius, K., Westerling, R., \& Tydén, T. (2004). Emergency contraceptive pills in Sweden: Evaluation of an information campaign. BJOG: An International Journal of Obstetrics and Gynaecology, 111(8), 820-827.

MacKinnon, D., Lockwood, C. M., Hoffman, J. M., West, S. G., \& Sheets, V. (2002). A comparison of methods to test mediation and other intervening variable effects. Psychological Methods, 7(1), 83-104.

McAlister, A., Morrison, T. C., Hu, S., Meshack, A. F., Ramirez, A., Gallion, K., Rabius, V., \& Huang, P. (2004). Media and community campaign effects on adult tobacco use in Texas. Journal of Health Communication, 9(2), 95-109.

McCombie, S., Hornik, R. C., \& Anarfi, J. K. (2002). Effects of a mass media campaign to prevent AIDS among young people in Ghana. In R. C. Hornik (Ed.), Public health communication: Evidence for behavior change (pp. 147-162). Mahwah, NJ: Lawrence Erlbaum. 
McDivitt, J. A., Zimicki, S., \& Hornik, R. C. (1997). Explaining the impact of a communication campaign to change vaccinaton knowledge and coverage in the Philipines. Health Communication, 9(2), 95-119.

Meyer, G., Roberto, A. J., \& Atkin, C. K. (2003). A radio-based approach to promoting gun safety: Process and outcome evaluation implications and insights. Health Communication, 15(3), 299-319.

Michie, S. \& Abraham, C. (2004). Interventions to change health behaviours: Evidence-based or evidence-inspired? Psychology and Health, 19(1), 29-49.

Miller, C. L., Wakefield, M., \& Roberts, L. (2003). Uptake and effectiveness of the Australian telephone Quitline service in the context of a mass media campaign. Tobacco Control, 12, 53-58.

Miller, W. R., Toscova, R. T., Miller, J. H., \& Sanchez, V. (2000). A theory-based motivational approach for reducing alcohol/drug problems in college. Health Education and Behavior, 27(6), 744-759.

Mizuno, Y., Kennedy, M., Weeks-Norton, K., \& Myllyluoma, J. (2002). An examination of adolescents who were and were not exposed to "Teens Stopping AIDS": Reaching the hard-to-reach. Journal of Health Communication, 7(3), 197-203.

Mohammed, S. (2001). Personal communication networks and the effects of an entertainmenteducation radio soap opera in Tanzania. Journal of Health Communication, 6(2), 137-154.

Moreau, C., Bajos, N., \& Bouyer, J. (2002). Evaluation of a mass media campaign on contraception in France. The European Journal of Contraception and Reproductive Health Care, 7(2), 105-113.

Myhre, S. L. \& Flora, J. A. (2000). HIV/AIDS communication campaigns: Progress and prospects. Journal of Health Communication, 5(Suppl.), 29-45.

Nishtar, S., Mirza, Y. A., Jehan, S., Hadi, Y., Badar, A., Yusuf, S., \& Shahab, S. (2004). Newspaper articles as a tool for cardiovascular prevention programs in a developing country. Journal of Health Communication, 9(4), 355-369.

Noar, S. M. (In press). A health educator's guide to theories of health behavior. International Quarterly of Community Health Education.

Noar, S. M. \& Zimmerman, R. S. (2005). Health behavior theory and cumulative knowledge regarding health behaviors: Are we moving in the right direction? Health Education Research: Theory \& Practice, 20(3), 275-290.

Noar, S. M., Clark, A., Cole, C., \& Lustria, M. (In press). Review of interactive safer sex websites: Practice and potential. Health Communication.

Oh, M. K., Grimley, D. M., Merchant, J. S., Brown, P. R., Cecil, H., \& Hook, E. W. (2002). Mass media as a population-level intervention tool for Chlamydia trachomatis screening: Report of a pilot study. Journal of Adolescent Health, 31, 40-47.

Owen, L. (2000). Impact of a telephone helpline for smokers who called during a mass media campaign. Tobacco Control, 9, 148-154.

Paisley, W. J. (2001). Public communication campaigns: The American experience. In R. E. Rice \& C. K. Atkin (Eds.), Public communication campaigns (3rd ed., pp. 3-21). Thousand Oaks, CA: Sage.

Palmgreen, P. \& Donohew, L. (2003). Effective mass media strategies for drug abuse prevention campaigns. In Z. Slobada \& W. J. Bukoski (Eds.), Handbook of drug abuse prevention: Theory, science, and practice (pp. 27-43). New York: Kluwer Academic/Plenum Publishers.

Palmgreen, P., Donohew, L., Lorch, E. P., Hoyle, R. H., \& Stephenson, M. T. (2001). Television campaigns and adolescent marijuana use: Tests of sensation seeking targeting. American Journal of Public Health, 91, 292-296.

Palmgreen, P., Lorch, E. P., Stephenson, M. T., Donohew, L., Hoyle, R. H., \& Sweatt, S. (2005, December). Effects of the Office of National Drug Control Policy's marijuana initiative campaign on at-risk youth. Paper presented at the annual meeting of the American Public Health Association, Philadelphia, PA. 
Perloff, R. M. (2003). The dynamics of persuasion: Communication and attitudes in the 21st century. (2nd ed.). Mahwah, NJ: Lawrence Erlbaum.

Pierce, J. P., Macaskill, P., \& Hill, D. (2002). Long-term effectiveness of the early mass media led antismoking campaigns in Australia. In R. C. Hornik (Ed.), Public health communication: Evidence for behavior change (pp. 57-72). Mahwah, NJ: Lawrence Erlbaum.

Randolph, W. \& Viswanath, K. (2004). Lessons learned from public health mass media campaigns: Marketing health in a crowded media world. Annual Review of Public Health, 25, 419-437.

Ratcliffe, J., Cairns, J., \& Platt, S. (1997). Cost-effectiveness of a mass media-led anti-smoking campaign in Scotland. Tobacco Control, 6(2), 104-110.

Reger, B., Cooper, L., Booth-Butterfield, S., Smith, H., Bauman, A., Wootan, M., Middlestadt, S., Marcus, B., \& Greer, F. (2002). Wheeling walks: A community campaign using paid media to encourage walking among sedentary older adults. Preventive Medicine, 35(3), 285-292.

Reger, B., Wootan, M. G., \& Booth-Butterfield, S. (2000). A comparison of different approaches to promote community-wide dietary change. American Journal of Preventive Medicine, 18(4), 271-275.

Reger, B., Wootan, M. G., \& Booth-Butterfield, S. (1999). Using mass media to promote healthy eating: A community-based demonstration project. Preventive Medicine, 29(5), 414-421.

Renger, R., Steinfelt, V., \& Lazarus, S. (2002). Assessing the effectiveness of a communitybased media campaign targeting physical inactivity. Family and Community Health, 25(3), 18-30.

Roccella, E. J. (2002). The contributions of public health education toward the reduction of cardiovascular disease mortality: Experiences from the national high blood pressure education program. In R. C. Hornik (Ed.), Public health communication: Evidence for behavior change (pp. 73-84). Mahwah, NJ: Lawrence Erlbaum.

Rogers, E. M. (1996). Up-to-date report. Journal of Health Communication, 1(1), 15-25.

Rogers, E. M. \& Storey, J. D. (1987). Communication campaigns. In C. R. Berger \& S. H. Chafee (Eds.), Handbook of communication science (pp. 817-846). London: Sage.

Rosenthal, R. (1991). Meta-analytic procedures for social research. Newbury Park, CA: Sage.

Rothman, A. J. (2004). "Is there nothing more practical than a good theory?': Why innovations and advances in health behavior change will arise if interventions are used to test and refine theory. International Journal of Behavioral Nutrition and Physical Activity, 1(1), 1-11.

Salmon, C. T. \& Atkin, C. (2003). Using media campaigns for health promotion. In T. L. Thompson, A. M. Dorsey, K. I. Miller, \& R. Parrott (Eds.), Handbook of Health Communication (pp. 285-313). Mahwah, NJ: Lawrence Erlbaum.

Secker-Walker, R. H., Worden, J. K., Holland, R. R., Flynn, B. S., \& Detsky, A. S. (1997). A mass media programme to prevent smoking among adolescents: Costs and cost effectiveness. Tobacco Control, 6(3), 207-212.

Siegel, M. \& Biener, L. (2000). The impact of an antismoking media campaign on progression to established smoking: Results of a longitudinal youth study. American Journal of Public Health, 90(3), 380-386.

Singhal, A. \& Rogers, E. M. (2003). Combating AIDS: Communication strategies in action. Thousand Oaks, CA: Sage.

Slater, M. D. (1996). Theory and method in health audience segmentation. Journal of Health Communication, 1(3), 267-285.

Slater, M. D. (1999). Integrating application of media effects, persuasion, and behavior change theories to communication campaigns: A stages-of-change framework. Health Communication, 11(4), 335-354. 
Sly, D. F., Heald, G. R., \& Ray, S. (2001a). The Florida "truth" anti-tobacco media evaluation: Design, first year results, and implications for planning future state media evaluations. Tobacco Control, 10, 9-15.

Sly, D. F., Hopkins, R. S., Trapido, E., \& Ray, S. (2001b). Influence of a counteradvertising media campaign on initiation of smoking: The Florida "truth" campaign. American Journal of Public Health, 91(2), 233-238.

Sly, D. F., Trapido, E., \& Ray, S. (2002). Evidence of the dose effects of an antitobacco counteradvertising campaign. Preventive Medicine, 35(5), 511-518.

Smith, W. (2002). From prevention vaccines to community care: New ways to look at program success. In R. C. Hornik (Ed.), Public health communication: Evidence for behavior change (pp. 327-356). Mahwah, NJ: Lawrence Erlbaum.

Snyder, L. B. \& Hamilton, M. A. (2002). A meta-analysis of U.S. health campaign effects on behavior: Emphasize enforcement, exposure, and new information, and beware the secular trend. In R. C. Hornik (Ed.), Public health communication: Evidence for behavior change (pp. 357-384). Mahwah, NJ: Lawrence Erlbaum.

Stead, M., Tagg, S., MacKintosh, A. M., \& Eadie, D. (2005). Development and evaluation of a mass media theory of planned behaviour intervention to reduce speeding. Health Education Research, 20(1), 36-50.

Storey, D., Boulay, M., Karki, Y., Heckert, K., \& Karmacha, D. M. (1999). Impact of the integrated radio communication project in Nepal, 1994-1997. Journal of Health Communication, 4(4), 271-295.

Street, R. L., Gold, W. R., \& Manning, T. (Eds.) (1997). Health promotion and interactive technology: Theoretical applications and future directions. Mahwah, NJ: Lawrence Erlbaum.

Surkan, P. J., Dejong, W., Herr-Zaya, K. M., Rodriguez-Howard, M., \& Fay, K. (2003). A paid radio advertising campaign to promote parent-child communication about alcohol. Journal of Health Communication, 8(5), 489-495.

Tambashe, B. O., Speizer, I. S., Amouzou, A., \& Djangone, A. M. R. (2003). Evaluation of the psamao "Roulez Protégé" mass media campaign in Burkina Faso. AIDS Education and Prevention, 15(1), 33-48.

Tamir, D., Polachek, D., Zivlin, O., Amikam, Y., Avraham, M., \& Weinstein, R. (2001). Smoking prevention campaign for youth in Israel. Public Health Reviews, 29(2-4), 185-194.

Thombs, D. L. \& Hamilton, M. J. (2002). Effects of a social norm feedback campaign on the drinking norms and behavior of division 1 student-athletes. Journal of Drug Education, 32(3), 227-244.

Thorson, E. \& Beaudoin, C. E. (2004). The impact of a health campaign on health social capital. Journal of Health Communication, 9(3), 167-194.

Trussell, J., Koenig, J., Vaughan, B., \& Stewart, F. (2001). Evaluation of a media campaign to increase knowledge about emergency contraception. Contraception, 63(2), 81-87.

Valente, T. W. (2001). Evaluating communication campaigns. In R. E. Rice \& C. K. Atkin (Eds.), Public communication campaigns (3rd ed., pp. 105-124). Thousand Oaks, CA: Sage.

Valente, T. W. \& Saba, W. P. (2001). Campaign exposure and interpersonal communication as factors in contraceptive use in Bolivia. Journal of Health Communication, 6(4), 303-322.

Vaughan, P. W. \& Rogers, E. M. (2000). A staged model of communication effects: Evidence from an entertainment-education radio soap opera in Tanzania. Journal of Health Communication, 5(3), 203-229.

Vaughan, P. W., Rogers, E. M., Singhal, A., \& Swalehe, R. M. (2000). Entertainmenteducation and HIV/AIDS prevention: A field experiment in Tanzania. Journal of Health Communication, 5(3), 81-101.

Wallack, L. M. (1981). Mass media campaigns: The odds against finding behavior change. Health Education Quarterly, 8(3), 209-261. 
Willemsen, M. C., de Vries, H., van Breukelen, G., \& Genders, R. (1998). Long-term effectiveness of two Dutch work site smoking cessation programs. Health Education and Behavior, 25(4), 418-435.

Williams, A. F., Wells, J. K., \& Reinfurt, D. W. (2002). Increasing seat belt use in North Carolina. In R. C. Hornik (Ed.), Public health communication: Evidence for behavior change (pp. 85-96). Mahwah, NJ: Lawrence Erlbaum.

Wimbush, E., MacGregor, A., \& Fraser, E. (1998). Impacts of a national mass media campaign on walking in Scotland. Health Promotion International, 13(1), 45-53.

Witte, K. (1992). Putting the fear back into fear appeals: The extended parallel process model. Communication Monographs, 59, 329-349.

Witte, K., Cameron, K. A., Lapinski, M., \& Nzyuko, S. (1998). A theoretically based evaluation of HIV/AIDS prevention campaigns along the transAfrica highway in Kenya. Journal of Health Communication, 3(4), 345-367.

Worden, J. K. \& Flynn, B. S. (2002). Using mass media to prevent cigarette smoking. In R. C. Hornik (Ed.), Public health communication: Evidence for behavior change (pp. 23-34). Mahwah, NJ: Lawrence Erlbaum.

Wray, R. J., Hornik, R. M., Gandy, O. H., Stryker, J., Ghez, M., \& Mitchell-Clark, K. (2004). Preventing domestic violence in the African American community: Assessing the impact of a dramatic radio serial. Journal of Health Communication, 9(1), 31-52.

Zimicki, S., Hornik, R. C., Verzosa, C. C., Hernandez, J. R., de Guzman, E., Dayrit, M., Fausto, A., \& Lee, M. B. (2002). Improving vaccination coverage in urban areas through a health communication campaign: The 1990 Philippines experience. In R. C. Hornik (Ed.), Public health communication: Evidence for behavior change (pp. 197-218). Mahwah, NJ: Lawrence Erlbaum.

Zimmerman, R. S., Palmgreen, P., Noar, S. M., Lustria, M. L. A., Lu, H. Y., \& Horosewski, M. L. (In press). Effects of a televised two-city safer sex mass media campaign targeting high sensation-seeking and impulsive decision-making young adults. Health Education \& Behavior. 